A question of finding harmony: A grounded theory study of clinical psychologists' experience of addressing spiritual beliefs in therapy

\author{
Jon P. Crossley* \\ Department of Clinical Psychology, Leicester Psychosocial Rehabilitation Service, Leicester, UK \\ Denis P. Salter \\ Centre for Applied Psychology, University of Leicester, UK
}

Word Count: 6985

*Correspondence to Dr J. P. Crossley, Department of Clinical Psychology, Leicester Treatment and Recovery Service, Sandringham Suite, Windsor House, Troon Way Business Centre, Humberstone Lane, Leicester, LE4 9HA.

E-mail: jon.crossley@leicspart.nhs.uk

Tel: 01162867711

Fax: 01162841244 


\title{
A question of finding harmony: A grounded theory study of clinical psychologists' experience of addressing spiritual beliefs in therapy
}

\begin{abstract}
In spite of the increasing emphasis upon spirituality in the psychological literature, research continues to highlight concerns that issues relating to spirituality are regularly overlooked within a therapeutic setting. The aim of the current study was to develop an account of the way in which clinical psychologists understand and address spirituality within therapy. Semi-structured interviews were conducted with eight clinical psychologists. The transcripts were analysed using the qualitative methodology of grounded theory, which also informed the data collection process. Two core categories were developed and termed 'spirituality as an elusive concept' and 'finding harmony with spiritual beliefs'. The diversity of meaning surrounding spirituality and the relative lack of engagement was found to create difficulty for constructing spirituality coherently as a concept. When specifically considering methods for identifying and addressing spiritual beliefs, contrasting approaches were identified. This diversity in understanding and approach has implications for the process and outcome of therapy, which are discussed in detail. Recommendations are suggested for developing spirituality as a more coherent and accessible concept, both within professional dialogue and the therapeutic context.
\end{abstract}

The position of spirituality within the practice of clinical psychology is far from clear. The ambiguity that surrounds the issue continues to manifest itself in debates about the relevance of spirituality to clinical psychology (e.g. King-Spooner 2001; Newnes, 2001; Smail, 2001), with Frosh's (1999) somewhat irreverent depiction of the topic as 'Jung verses Freud' highlighting the length of time that the debate has continued. A contributory factor to the discussion would appear to be the diverse and complex nature of the concept of spirituality. This is a modern development, as the word spirituality was only used in a religious or devotional sense in the early twentieth century (Wulff, 1997). Currently however spirituality is consistently used as a wider, more inclusive term than religion. Attempts within the psychological literature to define the construct reveal a range of concepts that vary greatly in their focus and emphasis.

Some definitions of spirituality concentrate upon the issue of transcendence. From this perspective, spirituality may relate to beliefs or the sense of relationship with powers 
transcending the present context of reality (King, Speck and Thomas, 1999). Other definitions similarly embrace the dualistic approach of distinguishing the worlds of spirit and matter, but without reference to transcendent forces. In this context, spirituality refers to the perspective or aspect in which the world is held distinct from the content of life (Hayes, 1984), or to a quest for meaning that is beyond the material aspects and the impermanence of things in life (Nino, 1997). Another approach is to define spirituality as a particular and distinct experience, for example when one attends only to the present and ceases to be pre-occupied with the past or the future, with concerns and anxieties (Rowe, 2001). Other constructions focus upon the values individuals hold. From this perspective spirituality may be either idiosyncratic and personal, relating to each individual's unique value systems (Duffy, 1998), or it may be concerned with specific attitudes and values such as respect and compassion towards all life (Haug, 1998). This tendency for definition to reveal numerous nuances of form and content has ensured that it has been problematic to develop reference points for discussion and investigation (Nino, 1997). The conclusion that one inevitably arrives at is that "spirituality is a vague thing" (Samuels, 1998, p.349); "a Humpty Dumpty word that means whatever the speaker wants it to mean" (Rowe, 2001, p.41).

\section{The relationship between psychology and spirituality}

There have been attempts by several authors to bridge the traditional dissociation between spirituality and psychology, perhaps most famously Jung, who was one of the first psychologists to recognise the relevance of faith and religious practice to the workings of the human psyche (Dry, 1961). More recently there have been several indications that psychological interest in spirituality is increasing. Numerous books about spirituality within therapy and mental health care have been published (Clarke, 2001; King-Spooner and Newnes, 2001; Swinton, 2001; West, 2000), special sections or issues on spirituality and psychotherapy have appeared in Couseling and Values (Helminiak, 2001a) and the American Psychologist (Miller and Thoresen, 2003) and the notion of spiritual intelligence has been introduced (Zohar and Marshall, 2000). There has also been the introduction of the diagnostic category 'Religious or Spiritual Problem' to the Diagnostic and Statistical Manual of Mental Disorders (American Psychiatric Association, 1994). Within the mainstream academic psychology literature however 
there is only a very limited focus on spirituality, and research within this area has been neglected (Miller and Thoresen, 2003). It has been described as perhaps the most unexamined issue of diversity within the field of mental health (Gutsche, 1994).

By contrast, there is evidence that spirituality in its various guises has ongoing significance across society. In the United States at least, the number of people who report that they engage in some spiritual practice and have spiritual experiences is increasing (Lukoff, Lu and Turner, 1998). Whether this is related to changes in behaviour or merely to changes in the way that spiritual activity is understood, it nevertheless reflects growing reference to spirituality. It is further argued that the visibility of spiritual concerns is increasing, as spiritual matters that were previously cultivated within the private realm of traditional religion have more recently been brought into the arena of the secular community (Nino, 1997). Issues such as immortality have been relocated as universal concerns evident in each of our lives, for example in biological modes where we have the sense of living on in our children, or in creative modes where our individual works continue their influence after our death (Lifton, 1987). The enduring significance of meaning and purpose, and of death and immortality, ensure that the realm of spirituality should not be relegated to the fringes of psychology. Belzen (1999) argues that the importance of religion alone across every culture in history indicates that it is an element of human life that may not be ignored by psychology. The danger emphasised by Gutsche (1994) from not paying enough attention to spirituality, is that the chasm between therapist and client is too great.

\section{Consideration of spirituality within therapy}

The ambiguity surrounding spirituality and the limited emphasis in psychological debate increases the potential for spirituality to be overlooked in a therapeutic setting. This is a concern that has been frequently expressed (Hathaway, Scott and Garver, 2004; Myers and Baker, 1998) and many potential processes by which spiritual aspects may remain unheeded have been documented. Therapist factors include remaining silent when attempting to be neutral (Adams, 1995) and holding a negative view of spiritual experiences (Prest and Keller, 1993). Research has found that in the United States at least it is clinical psychologists' personal orientations towards spirituality rather than the 
limited clinical training that they receive in this area that are the primary determinants of their clinical approach to spirituality in professional practice (Shafranske and Malony, 1990). Client factors include having spiritual aspects split off and hidden (Reinertsen, 1993) and perceiving that the therapist will not be able to understand the beliefs that are held (Lindgren and Coursey, 1995). Broader contextual factors meanwhile include the quest for scientific status within psychology which has allowed the discipline to avoid the large, enduring questions of ultimate concern, labelling such as 'unscientific' and 'a question of personal belief' (Lifton, 1987).

\section{Rationale for the study}

Despite these concerns that spirituality is frequently overlooked or is considered in a less than systematic manner by clinical psychologists, there is actually very little direct evidence to confirm or challenge this conclusion as detailed studies of the way that clinical psychologists do approach spirituality have not been conducted. This lack of evidence creates a vacuum of knowledge both about current practice and about the training needs of clinical psychologists in this area. It was therefore decided to conduct a study addressing the question of how clinical psychologists address spirituality in therapy. The research also explored the participants' understanding of the term spirituality and their attitude towards it, in view of the ambiguity surrounding the topic and the positive relationship between therapist values and the process and outcome of therapy respectively. The qualitative methodology of grounded theory was used for data analysis, and it also informed data collection. Qualitative methodology was chosen to facilitate the hypothesis generation (rather than hypothesis testing) and in-depth examination of meanings required in new and developing areas of study (Henwood and Pidgeon, 1995; Parker, 1994).

\section{Method}

\section{Participants}

Eight qualified clinical psychologists (four male, four female) participated in the study. The sample size reflects the time constraints imposed by research conducted as part of 
doctoral qualification. All of the participants were employed within the National Health Service. They operated in adult $(n=5)$, child and adolescence $(n=2)$ and older adult $(n=1)$ settings. The length of time practising as a qualified psychologist ranged from 3 months to 24 years (mean of 11.75 years). The participants described their theoretical orientations as eclectic $(n=2)$, cognitive-behavioural $(n=2)$, personal construct $(n=2)$, systemic $(n=1)$ and community psychology $(n=1)$. Participants described a broad range of personal spiritual values and beliefs, including tentative alignments with religious frameworks, atheist positions and values distinct from transcendent notions.

\section{The researcher}

The researcher (the first author) at the time of the study was in the final year of clinical psychology training. The second author was an experienced clinical psychologist, and acted in a supervising role. The former describes himself as a Christian, the latter as an Agnostic Buddhist (Batchelor, 1997). Both authors hold contextual constructionist epistemological positions (Madill, Jordan and Shirley, 2000). The researcher was aware that his experience of clinical practice and training was linked to his perspective of spirituality being rarely discussed within the clinical psychology profession, and he used reflexive techniques to attempt to identify and manage the impact of his assumptions and values.

\section{Procedure}

\section{Recruitment of participants}

The exploratory nature of the study dictated the value of participants representing a range of psychological practice, without being a representative sample. Two methods were used to recruit participants. Firstly, an invitation to take part in the study was given at the local area meeting of clinical psychologists, with all volunteers accepted as participants. The other strategy involved using theoretical sampling to enhance the theory, that is the process of simultaneously collecting and analysing data and using the understanding gained to guide further data collection (Glaser and Strauss, 1967). Two participants who were identified as 'deviant cases' to the developing theoretical account were thereby recruited using this approach. One of these participants had thoroughly considered and written about spirituality, as a deviant case to the emerging category of 'being unfamiliar 
with spirituality'. The other worked in an older adult setting, which was suggested by participants to be an area where spirituality would be discussed more frequently, as a deviant case to the emerging category of 'not talking about spirituality'.

\section{Interview Guide}

A semi-structured interview guide was used to direct the conversation towards the previously identified areas of interest, without dictating the process (Barker, Pistrang and Elliott, 1994; King, 1996). The first area was participants' constructions of spirituality. Participants were asked to describe spirituality; the values, beliefs and practices that they thought were spiritual; the relationship between spirituality and religion. Another area concerned attitudes and perspectives towards spirituality. Participants were asked to describe the nature and importance of their own spiritual values or beliefs; the impact of both clients' and their own attitudes to spirituality on therapeutic process and outcome; their consideration of and training in the area. Finally the main research question of participants' experience of addressing spirituality in therapy was explored. Participants were asked to identify the emphasis they placed upon considering and exploring the client's spirituality; the spiritual issues that were important to address in therapy; the ways their approach varied with the spiritual orientation of the client. There were also requests for examples.

As a further aspect of the broad process of theoretical sampling, the interview guide was developed throughout the research process and was increasingly used to direct the conversation towards emerging themes that were conceptually rich. These themes included participants' familiarity with and use of the concept of spirituality and factors influencing the focus on spirituality in therapy.

\section{Data Analysis}

The core procedures of data coding, memo-writing and theoretical sampling were applied rigorously to allow the full data set (each interview in its entirety) to be analysed. This allowed codes and categories to be generated and validated (Charmaz, 1995; Glaser and Strauss, 1967; Strauss and Corbin, 1990). It was understood that the categories were developed rather than discovered and reflected the authors' personal and cultural 
perspectives to some extent, which is congruent with the authors' constructionist epistemology (Madill et al., 2000).

\section{Coding}

The initial task of line-by-line coding involved considering each line of data in turn, comparing the data with the content of other codes and conceptualising the phenomena that were present by using specific labels or codes. This example illustrates the process.

- what I end up with myself, is that sort of, I think it was, it was from Kant, that it came originally, something about, do unto others, as you would, do unto you, (Clive: 167, 568-570)

The codes that were generated from this example were personal construction ('what I end up with myself'), borrowed concept ('it was from Kant, that it came originally') and specific value system ('do unto others, as you would, do unto you').

Subsequent focused coding allowed the data to be treated at a more conceptual and abstract level, by comparing and grouping codes together to generate categories with specified properties or characteristics.

\section{Memo-writing and theoretical sampling}

Memos were used to identify and describe the properties of categories and also to search for underlying assumptions within the participants' accounts, in order to define the categories more fully (Charmaz, 1995). The understanding that was gained from focused coding and memo writing regarding the discrepancies and gaps in the emerging account was used directly to guide further data collection and develop the theory. An example was identifying through memos that participants assumed socially positive values when defining spirituality as an individual's personal values. In later interviews it was therefore enquired whether spirituality could also include other values such as selfishness. This process of theoretical sampling led to saturation within the theoretical account, to a suitable level of conceptual density and richness (Strauss and Corbin, 1990). 


\section{Methods to enhance quality}

Numerous techniques have been utilised throughout the research process and in this written representation of the study to enhance quality. Techniques to enhance the 'trustworthiness' of the study included intensive and prolonged engagement with the material, regular peer discussion of findings and process and the description of the researchers' orientations in this account (Merrick, 1999; Stiles, 1993). Reflexive procedures such as maintaining a reflexive journal (Lincoln and Guba, 1985) and supervision were consistently directed at the interview process, the data and the developing account. Coherence and integration were established in the development and presentation of the findings by adopting a consistent hierarchical structure that organises the account around core categories (Elliot, Fischer and Rennie, 1999).

\section{Results}

This section contains an account of the data, which is organised around two core categories. The first core category of 'spirituality as an elusive concept' provides a broad description of the participants' conceptual relationship to spirituality, that is how they understand spirituality and engage with it at a theoretical level.

The second core category of 'finding harmony with spiritual beliefs' describes the participants' clinical relationship to a specific dimension of spirituality, that is spiritual beliefs. This dimension was the aspect of spirituality that was focused on most extensively during discussion of spirituality in therapy, both in terms of the depth to which it was explored by individual participants and the consistency with which each participant considered it. Other dimensions of spirituality were considered in relation to therapy to a lesser extent and more sporadically, and therefore have not been included in this exploration of how spirituality is addressed in order to promote a more detailed and precise examination. Discussion of the second core category is therefore more narrowly focused than the first, in the sense that one specific dimension of spirituality is considered. 
Both of the core categories (denoted numerically) are described by summarising the main categories (denoted alphabetically) that exist beneath the core category. The main categories are described by reference to the properties that comprise the categories. Excerpts from the interviews are provided to substantiate the analytic claims that are made.

\section{1) Spirituality as an elusive concept}

The concept of spirituality was elusive to participants in two ways. It was firstly a diverse construct with several meanings that were simultaneously overlapping and contradictory. This caused participants to feel confused, as if they were unable to grasp the fundamental nature of spirituality. Spirituality also felt elusive to participants because it was not a concept that the field of clinical psychology was actively engaging with. Participants suggested a range of reasons for this lack of engagement, including the paucity of language available for discussing spirituality, the discomfort associated with discussion of the topic and factors related to personal background.

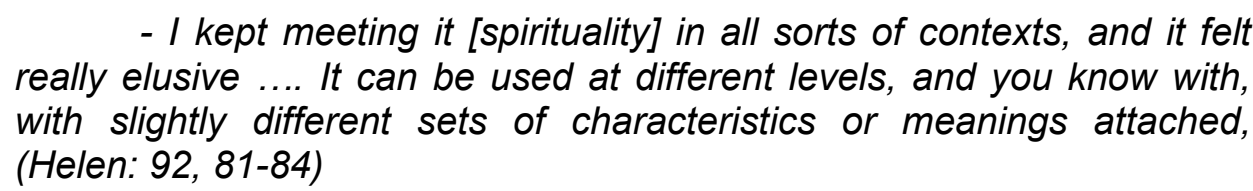

\section{1a) The diversity of spirituality}

The participants conceptualised and defined spirituality in many different ways. Within this diversity in understanding there was a consistent acceptance of the breadth of meaning surrounding spirituality; that is, participants were aware that the concept of spirituality could be understood in numerous ways. Several participants actually moved freely between different definitions in their accounts, and used spirituality to refer to a range of phenomena, for example Claire.

- for me spirituality's tied very much up with religion, and that might not necessarily, that doesn't have to be the case but ... that's the way I sort of see it. (Claire: 135, 1165-1168) 
- I'm using spiritual to equate with very much thinking, he was a very deep thinking sort of man ... he struck me as being spiritual but I suppose he struck me as being, erm, deep thinking maybe (Claire: 125, 642-653)

A further theme within the diversity in conceptualisation was the participants' desire to understand spirituality more broadly than religion. The few participants who did report associating spirituality exclusively with religion actually also used alternative understandings of spirituality at other points during the interview, thereby highlighting their tacit understanding of the expansive nature of the term (as with the above example of Claire). Some participants attempted to coherently make sense of the breadth of meaning surrounding spirituality by separating the concept into two distinct aspects or elements, as Peter describes.

- there's two elements to it [spirituality]. One is about the, the religious practice ... but there's, there's a broader one as well about erm, meaning if you like and err, a person's sense of self. (Peter: 89, 971978)

This method of categorisation was understood to be important from the analysis, as it provided participants with a way of dividing the more restrictive conceptualisations of spirituality from the more expansive ones. Alongside religious practice in the former group could be placed the other shared belief systems or philosophical frameworks that were understood by some participants as spirituality, for example humanist positions where everyone is treated as having inherent value. Religious and humanist conceptualisations can be grouped together using this method of categorisation, despite differing with regard to the issue of transcendence, as they are united by having a shared framework and therefore boundaries as to what may be seen as spirituality. This distinguishes these more restrictive conceptualisations from the more expansive idea of spirituality as 'individual meaning' or 'sense of self' that Peter and other participants referred to, where there are potentially no limitations as to what is regarded as spirituality.

- Spiritual issues would be internal, internal to me and, and it would involve some instructions that I had and what I did, mainly true for me in my, erm, life. So it's a quite personal, individual, internal thing. (Susan: 25, 78-80) 
- it's [spirituality] very individualistic, and there's nothing like right or wrong in that, and it's each one what they want to believe and, what they want to follow. So I guess the range is infinite because, it's each one individually what they want to. (Kathryn: 3, 165-177)

A concern that was raised about adopting the very broad and relativistic concept of spirituality as 'individual meaning' was that all behaviour or values could potentially then be viewed as spiritual, including attitudes such as selfishness or greed for example that were not included within the other definitions of spirituality that were based on shared frameworks. From this perspective it was suggested that boundaries to the concept of spirituality were necessary.

- this is the problem with that. There's quite a risk in that, in that what's the difference between that and just being bloody selfish or, yeah, it's a question of where do my values transgress yours or, what are the boundaries (Clive: 168, 628-633)

In addition to the numerous definitions of spirituality therefore, there was a specific disagreement between the participants' accounts about how broad the concept ought to be. As a result of the participants' awareness of both the general diversity in meaning surrounding spirituality and their own struggle to coherently understand the construct, it was generally accepted that the concept was difficult to grasp and to discuss.

- It's a difficult topic .... just by its very nature it, you, for every individual they might have their own definition of it, (Peter: 89, 946-957)

- I suppose the nature of sort of, spirituality as well's felt quite, it's felt quite nebulous, (Claire: 135, 1169-1170)

\section{1b) Not engaging with spirituality}

The elusive nature of spirituality was also characterised by the lack of discussion of the topic within the professional and training context of clinical psychology. Some participants identified specific contexts where they had discussed particular dimensions of spirituality, for example discussion of religious issues in a forum for exploring 
cultural differences. Several participants however recorded that they had never thought about the concept or discussed the issue in relation to work throughout their careers. The concept was certainly emphasised as being absent from clinical training courses.

- my understanding certainly having gone through training and, and working now is that, erm, it's not, something that's addressed .... it's something that's never, ever been addressed, sort of with me and I wouldn't, I haven't brought it up with anyone else, and probably wouldn't. (Claire: 117, 208-214)

Three core themes were identified as reasons for the lack of engagement with spirituality within clinical psychology, which make up the three properties of this category. Firstly, there was a strong emphasis in some of the interviews of the unease that is associated with debate on spirituality at a cultural level. It was suggested that across society generally people feel uncomfortable and embarrassed discussing ideas about the meaning or purpose of life. It was also emphasised that religion in particular is a sensitive subject that can be extremely divisive in certain cultures, making it an awkward subject to discuss.

- it's [spirituality] something that says there's more to life than this. And as such it's something that, particularly in English society is, mustn't, mustn't talk about it very much. It's an, it's embarrassing. (Clive: 167, 554-560)

Secondly, there was a theme of not engaging with spirituality because of factors related to the participant's background. Some participants reported not inquiring about spiritual beliefs, because of the limited significance of this area to the therapist.

- I have been struck by the fact it [spirituality] hasn't come up.... obviously as a therapist I haven't, because it's not, it's not central to how I view the world, I haven't asked it or pursued it, (Susan: 28, 277-282)

Other participants described shying away from aspects of spirituality such as religion, because of their personal experience of religion as a controversial and problematic area.

- I guess my, my general err, initially, which is changing now, 
would be, it's like stay away from religion, it's a sensitive area, especially maybe coming from $X$ because there's so many religions and .... it can cause problems, (Kathryn: 22, 1188-1197)

Finally there was a difficulty with the language that was available to discuss spirituality. Participants reported that there was a paucity of language available, and as a result they were forced to use clichés or words they considered inadequate when expressing their ideas. This therefore inhibited discussion of spirituality. It was also suggested that the language commonly used to discuss spirituality was related to the more traditional meaning of spirituality as religion which led to other potential dimensions not being discussed within the frame of spirituality, again limiting the discussion of spirituality within the context of clinical psychology.

- if you don't have a strong religious conviction in a traditional sense, then it's a difficult subject to talk about. Not in that it's emotionally or psychologically difficult. It's just difficult to find the words, because all the words that you have I think are couched in religious terms. So I guess there might be a danger when talking about spirituality, one might say, "no, it's not part of my life at the moment", but I think it is a part of most people's lives, but they call it something else. (Susan: 34, 583-591)

\section{2) Finding harmony with spiritual beliefs}

This section focuses on the way that participants addressed spiritual or religious beliefs in therapy. Participants specified that their fundamental aim when working therapeutically with clients who held spiritual beliefs was to act in ways that were aligned and actually 'in harmony' with the particular beliefs that were held. While it was suggested that this was a delicate and artful process, the analysis identified two specific aspects to this method, which were understanding the significant beliefs of the client and respecting those beliefs.

- this is more subtle in a way and I think that's, that's probably the art of therapy, and that if you're an effective therapist, you're working in a way which puts you in harmony with their spiritual beliefs. (Peter: 88, 886-890) 


\section{2a) Understanding beliefs}

It was emphasised by participants that one part of the practising psychologist's role is to be aware of the areas of life that are significant, and to understand their particular meaning to the individual. Hence it was suggested that the process of understanding spiritual beliefs and their impact upon an individual's experience of life is just one aspect of the assessment process whereby meaningful areas of life are explored and understood.

- if an area of, of living, of existence is significant to the client ... it's usually worth exploring, understanding at least, and then deploying what, whatever you do from there.... that applies to spirituality, as much as it would apply to any other area. (Harvey: 148, 667-675)

There were essentially two strategies described by participants for considering the beliefs of clients. Firstly some participants referred to direct assessment of spiritual beliefs, without the client having made prior reference to these.

- I always ask, well, almost always ask people if they've got any religious beliefs, (Clive: 165, 454-455)

The alternative approach consisted of waiting for the client to mention spiritual beliefs before considering this issue. One rationale that was cited for this method was the understanding that significant issues for the client including his or her spiritual beliefs would be conveyed without prompting during assessment.

- They would be the ones that would be, be declaring their thought processes. "This is what, I believe, this is where I am." I wouldn't ask them the question, "do you believe in a, do you have a religion, do you have spirituality". (Brian: 59, 1283-1287)

- if it's important to them, it comes up. Not in response to questions from me like, "what is your spirituality?" or, err, when they're just going through their whole life events and that, somehow I, I've found people, if it's important they do tell me. (Kathryn: 18, 984-992)

\section{2a) Respecting beliefs}

In order to be able to respect the beliefs of the client, it was suggested that it was necessary for the psychologist to arrest his or her own judgement about those beliefs and 
develop an empathic approach. Participants emphasised however that fundamental problems were encountered, when the client's spiritual understanding was perceived to be contributing to his or her distress. In such circumstances participants experienced difficulty understanding the appropriate process for respecting spiritual beliefs.

- It's also about recognising, that different people do have belief systems which guide their life entirely. I'm willing to respect those, and how, gosh and how difficult it is to find the line, up to which you're not abusing people's rights to hold those beliefs, (Helen: 100, 548-553)

Different strategies were described by participants when faced with the above situation. One approach involved withdrawing from the examination of a client's beliefs, in order to comply with the requirement to respect those beliefs. In one example this course of action left the participant perceiving that an opportunity to act therapeutically had been lost.

- she was very worried that her family would not go to heaven .... initially I caught myself trying to, sort of inquire more about it and then I realised this is an, this is something we couldn't take it any further .... it's a religious belief. I need to respect that and I need to, take it for what she says (Kathryn: 10, 499-507)

- I have a feeling that, if we simply had a chance to explore in this person it could help them. (Kathryn:15, 780-782)

A contrasting approach was to attempt to find a suitable method of understanding that lessened the distress, but that also fitted with the client's beliefs. In such cases the client was encouraged to re-examine significant aspects of his or her spiritual understanding, by considering alternative information that was consistent with his or her beliefs. In one example the psychologist questioned the client's understanding that the probability of a traumatic event reoccurring was unknown because it was completely in the hands of Allah, whose actions could not be predicted. Through carefully highlighting information that was consistent with the client's spiritual beliefs, the psychologist was able to facilitate a more adaptive understanding of Allah interacting consistently with the world, which suggested that the probability of the event reoccurring was actually very low and which thereby lessened the client's distress. 
- father said to me, 'Ah yes, it's in the hands of God, of Allah'.... but, then I had to, find ways of dealing with that because, that's different .... that's a very different message that he was wanting to give his child, from the one I would want to give. (Peter: 79, 425-440)

- we came to a kind of compromise in a way, but I think that conceded that ... things in the world are probable, and God is part of that. So for instance I mean the, the sun has, has risen in the sky every, every day for as long as, huh, ever.... So you can still believe in the power of God, but he, he, he works in certain consistent ways, which give rise to probability. (Peter: $80,447-459$ )

A final approach was to suggest to the client that he or she needed to discuss the distress and related beliefs with the relevant spiritual or religious leader. The particular context that was suggested for this approach was when the client was seeking advice about the validity of his or her spiritual beliefs.

- I have seen people where I ended, had to say, "I think you ought to go and talk to your minister or", because, the agony of, "can I really believe, these things?" And you're sitting there thinking, "well I don't'.(Clive: 179, 1207-1211)

\section{Discussion}

The findings of this study indicate there is considerable diversity in understanding and clinical approach to the issue of spirituality in therapy amongst clinical psychologists. At a conceptual level the findings emphasise that spirituality is an elusive construct within clinical psychology; it is a diverse and difficult topic that is not rigorously engaged with within training and professional debate. At a clinical level regarding spiritual beliefs specifically, the findings highlight the different approaches that are employed to achieve the goal of remaining in harmony with beliefs. The implications of these two findings are discussed in turn.

\section{Towards closer engagement with the concept of spirituality}

The perception of spirituality as nebulous and elusive was related not only to the lack of 
professional engagement with the concept, but also the ambiguity and breadth of meaning surrounding the construct (Samuels, 1998). The findings highlight that a fundamental difficulty with attempting to understand spirituality as a discrete and uniform concept is the impossibility of reconciling the infinite relativism of spirituality as individual meaning with the more precise boundaries of spirituality as religion for example or other shared frameworks. Models of spirituality have been introduced that provide a path through this dilemma, for example Helminiak's (2001a) adoption of Lonergan's (1972) "transcendental precepts" of being attentive, intelligent, reasonable and responsible (defined as the expression of the human spirit) as a framework for spirituality. These four precepts allow the expression of spirituality to comprise a considerable breadth of perspective and behaviour while simultaneously placing certain restrictions, such that attitudes including selfishness and solipsism are excluded. However, several objections have been raised about adopting such a model to represent spirituality (Marquis, Holden and Warren, 2001; Watts, 2001), causing Helminiak (2001b, p.250) to conclude that "the attempt to coherently integrate psychology and spirituality .... reveals that there are there are fundamental and deeply felt differences of opinion".

It would appear that the breadth of potentially contradictory meanings attached to spirituality prevents the development of a discrete model that integrates the different aspects of spirituality and gains consensus within the field. It may be concluded therefore that spirituality is best understood as a complex and multidimensional construct, with no single measure able to capture the essential meaning (Elkins, Hedstorm, Hughes, Leaf and Saunders, 1988; Miller and Thoresen, 2003). By conceptualising spirituality as multidimensional and focusing upon specific dimensions, Miller and Thoresen (2003) suggest that definitional issues actually become clearer. Acknowledgement of the different aspects of spirituality and clarification about intended dimensions prior to any discussion (Rowe, 2001) is therefore an important first stage to closer engagement to the idea of spirituality within psychology. Without such illumination debate becomes meaningless, and actually serves to maintain spirituality as the enigmatic and impenetrable concept that was indicated by the findings. 
Other factors within the findings that hindered engagement with aspects of spirituality include the sense of discomfort surrounding discussion of ideas such as purpose and meaning at a cultural level, which some authors have similarly alluded to (West, 2000). Some participants also emphasised the importance of their own personal experiences in steering them away from aspects such as spiritual beliefs, supporting the finding that it is psychologists' personal orientations towards religion and spirituality rather than clinical training that are the primary determinants of their clinical approach to these issues (Golsworthy and Coyle, 2001; Shafranske and Malony, 1990). The influence of cultural and personal biases suggests a lack of reflexive attention to these issues. Reflexive considerations regarding both cultural and personal values may therefore be identified as another necessary stage towards a more systematic approach to the broad concept of spirituality. The value of a reflexive approach in this area has been documented within the literature. Reinertsen (1993) for example reports that she noticed a shift towards more open discussion of religion within therapy, once she felt greater freedom to explore such themes herself.

A further important step towards more rigorous engagement with the concept of spirituality is clinical training. Reports have indicated the absence or rarity of discussion of religious or spiritual issues within training in the US (Lukoff et al., 1998; Shafranske \& Maloney, 1990), and the current findings suggest a similar situation in the UK. Several authors have provided coherent and compelling arguments for embracing aspects from spiritual traditions and models within clinical work, for example Buddhist approaches to issues of the self (Claxton, 1986; Epstein, 1995), models of forgiveness (Worthington, 2001) and transpersonal perspectives of psychosis (Clarke, 2001). Training is clearly required for such ideas to be integrated more fully into clinical psychology practice, and training would also encourage greater appreciation of the multidimensional nature of the concept of spirituality, enhancing its accessibility to the profession. Furthermore this would facilitate the development of appropriate clinical language for each of the key aspects of spirituality, which would help to overcome the obstacle of inadequate vocabulary that has been identified in the literature (KingSpooner, 2001; Rowe, 2001) as well as the findings. 


\section{Developing the art of finding harmony with beliefs}

The findings indicate that the issue of spiritual beliefs in therapy is fertile ground for discussion and consideration amongst clinical psychologists. The two steps of understanding and respecting beliefs are described, which allowed the participants to achieve the goal of remaining in harmony with the client's spiritual beliefs. Regarding the initial stage of understanding beliefs, the findings illustrate a desire by each of the participants to explore spiritual beliefs in the context of explicit indication from the client of the significance of this area. There was less consistency in approach between participants when there was not a disclosure of significant beliefs by the client. Some participants indicated that they routinely inquired about the presence and nature of beliefs, while others reported that they responded to the lead of the client. This disparity in approach was related to a distinction in participants' understanding of how spiritual concerns would be raised in therapy. The perspective that spiritual concerns are frequently hidden by the client and easily overlooked by the therapist was associated with the introduction of strategies to allow these ideas to become visible. The contrasting perspective, that spiritual matters will be raised by the client if significant, led to the therapist waiting for the client to introduce such ideas.

A review of the literature on religious counselling concludes that clients are often concerned with challenges or potential challenges to their values in therapy (Worthington, 1986). West (2000) highlights the "commonly accepted" (p.17) view that clients avoid exploring topics that their therapists are 'deaf to', and somehow pick this up without being told. The findings from this study illustrate that some participants were apathetic towards the area of spirituality and others actively shied away from it within the arena of clinical practice, because of the influence of their personal backgrounds in the absence of training in the area. Such approaches certainly would not facilitate disclosure of spiritual beliefs by clients and may actually inhibit it, indicating that prompting from the clinician would be required. A clear benefit of enquiry about beliefs from the therapist is that it informs the client that discussion of this area is sanctioned, allowing the client to speak about it more easily. Byng-Hall (1995) asserts that identifying areas of danger or conflict for the client early in therapy permits the 
therapeutic relationship to act more fully as a secure base, enabling greater exploratory work to occur. It may be concluded therefore that enquiry about spiritual beliefs should be more routinely included within clinical practice (Hathaway et al., 2004), particularly in the current culture within clinical psychology where the topic of spirituality is not rigorously engaged with and therefore may be avoided without specific motivation or intent.

When considering the second step of respecting beliefs, participants emphasised the importance of suspending one's own thoughts about the beliefs and empathising with the client's perspective. The observation of this heuristic is consistent with both the instruction in the Professional Practice Guidelines (Division of Clinical Psychology, 1995, Section 3.1.2, p.13) for psychologists not to "unreasonably impose their own values", and the 'principle of the exclusion of the transcendent'. This principle was specified originally by Flournoy (Wulff, 1997) and re-emphasised in later years by Jung (Dry, 1961). It asserts that psychologists should neither reject nor affirm the existence of the spiritual or transcendent object, as this is a philosophical matter that is beyond their domain of competence. However the interpretation of this principle is not straightforward (Wulff, 1997). At one extreme all variations in conception of the transcendent figure are understood to be beyond the realm of psychology and therefore have to be respected. At the other extreme all variations are viewed as historically conditioned expressions of the human mind and therefore may actually be explored and worked with.

The findings from the current study indicate variation between participants in their interpretation of the principle of respecting beliefs, and examples were provided that were towards the opposing extreme positions described above. In one example a participant withdrew from a potentially therapeutic discussion of spiritual beliefs because of the understanding that these beliefs needed to be respected. In a contrasting example, the conception of Allah as acting in an almost whimsical manner was questioned through discussion of the order in the universe, leading to an alternative conception of Allah as acting in a consistent manner which was helpful and adaptive for the client. 
This divergence in approach between psychologists when addressing spiritual beliefs is not surprising, given the lack of training in the area that participants reported and the shortage of adequate theoretical frameworks that clinicians are familiar with for guiding intervention with religious and spiritual dimensions (Golsworthy and Coyle, 2001). Models are gradually being introduced however that psychologists would benefit from becoming familiar with, in order to be more confident in discerning in which contexts there are opportunities for therapeutic involvement (Griffith and Griffith, 2002). Lovinger (1996) reports 10 markers of religious pathology that may be helpfully addressed in therapy, such as relinquishing responsibility when it is suggested for example that 'the devil made me do it'. He also asserts that one of the indices of mature religious adjustment is the awareness of complexity and ambiguity, which emphasises that there is frequently room for alternative perspectives and interpretations. Helminiak (2001a) also suggests that reinterpretation and even rejection of spiritual ideas are sometimes appropriate in therapy and proposes Lonergan's (1972) "transcendental precepts" as a framework to guide clinicians. Clearly these ideas need close consideration for as Bergin, Payne and Richards (1996) emphasise, a sensitive line exists between critiquing beliefs while pursuing psychological integrity and examining beliefs with pre-emptive judgments. In certain contexts as some participants indicated, the most useful and ethical decision may be to refer the individual to the spiritual or religious leader, or at least to liase with such (Bergin et al., 1996; Lovinger, 1996).

Given the complexity of these issues, this is another area that could helpfully be incorporated into clinical training. Without greater attention upon this topic the findings indicate that there is a danger of equating the need to respect spiritual beliefs with withdrawing from or avoiding the topic. The Professional Practice Guidelines (Division of Clinical Psychology, 1995) direct psychologists to pay particular attention to the influence of culture within which spiritual beliefs are regularly located, and therefore it may be concluded that avoidance of the area is not justifiable. As a legitimate facet of human diversity, spiritual beliefs need to be afforded the same consideration in therapy as all other forms of diversity (Bergin et al., 1996), and appropriate education and training is required for this to occur more routinely and effectively. 


\section{References}

Adams, N. (1995). Spirituality, science and therapy. Australian and New Zealand Journal of Family Therapy, 16(4), 201-208.

American Psychiatric Association (1994). Diagnostic and statistical manual of mental disorders, (4th edn.). Washington DC: American Psychiatric Association.

Barker, C., Pistrang, N. \& Elliott, R. (1994). Research methods in clinical and counselling psychology. Chichester: Wiley.

Batchelor, S. (1997). Buddhism without beliefs: a contemporary guide to awakening. London: Bloomsbury.

Belzen, J.A. (1999). The cultural psychological approach to religion: contemporary debates on the object of the discipline. Theory and Psychology, 9(2), 229-255.

Bergin, A.E., Payne, I.R. \& Richards, P.S. (1996). Values in psychotherapy. In E.P. Shafranske (Ed.), Religion and the clinical practice of psychology (pp.297-325). American Psychological Association: Washington DC.

Byng-Hall, J. (1995). Re-writing family scripts: improvisation and systems change. London: Guilford Press.

Charmaz, K. (1995). Grounded Theory. In J.A. Smith, R. Harre \& L.K.Langenhove (Eds.), Rethinking methods in psychology (pp. 27-49). London: Sage.

Clarke, I. (2001). Psychosis and spirituality: exploring the new frontier. London: Whurr.

Claxton, G. (1986). Beyond therapy: the impact of Eastern religions on psychological theory and practice. London: Wisdom.

Division of Clinical Psychology (1995). Professional practice guidelines. Leicester: Division of Clinical Psychology.

Dry, A. (1961). The psychology of Jung: a critical interpretation. London: Methuen.

Duffy, T. (1998). Spirituality, the counsellor and the church: can they journey together? Changes, 16(4), 309-317.

Elkins, D.N., Hedstorm, L.J., Hughes, L.L., Leaf, J.A. \& Saunders, C. (1988). Towards a humanisticphenomenological spirituality. Journal of Humanistic Psychology, 28(4), 5-18.

Elliott, R., Fischer, C.T. \& Rennie, D.L. (1999). Evolving guidelines for publication of qualitative research studies in psychology and related fields. British Journal of Clinical Psychology, 38, 215-229.

Epstein, M. (1995). Thoughts without a thinker: psychotherapy from a Buddhist perspective. New York: Basicbooks.

Frosh, S. (1999). What is outside discourse? Psychoanalytic Studies, 1(4), 381-390.

Glaser, B.G. \& Strauss, A.L. (1967). The discovery of grounded theory: strategies for qualitative research. Chicago: Aldine.

Golsworthy, R. \& Coyle, A. (2001). Practitioners' accounts of religious and spiritual dimensions in bereavement therapy. Counselling Psychology Quarterly, 14(3), 183-202.

Griffith, J.L. \& Griffith, M.E. (2002). Encountering the sacred in psychotherapy: how to talk with people 
about their spiritual lives. New York: Guilford Press.

Gutsche, S. (1994). Voices of healing: therapists and clients journey towards spirituality. Journal of Systemic Therapies, 13(3), 3-5.

Hathaway, W.L., Scott, S.Y. \& Garver, S.A. (2004). Assessing religious/spiritual functioning: a neglected domain in clinical practice? Professional Psychology: Research and Practice, 35(1), 97-104.

Haug, I.E. (1998). Including a spiritual dimension in family therapy: ethical considerations. Contemporary Family Therapy, 20(2), 181-194.

Hayes, S.C. (1984). Making sense of spirituality. Behaviorism, 12(2), 99-110.

Helminiak, D.A. (2001a). Treating spiritual issues in secular psychotherapy. Counseling and Values, 45(3), 163-189.

Helminiak, D.A. (2001b). Rejoinder and clarifications on Helminiak's (2001) "Treating spiritual issues in secular psychotherapy". Counseling and Values, 45(3), 237-251.

Henwood, K. \& Pidgeon, N. (1995). Grounded theory and psychological research. The Psychologist, 8(3), $115-118$

King, E. (1996). The use of the self in qualitative research. In J. T. E. Richardson (Ed.), Handbook of qualitative research methods for psychology and the social sciences (pp. 175-188). Leicester: BPS Books.

King, M., Speck, P. \& Thomas, A. (1999). The effect of spiritual beliefs on outcome from illness. Social Science and Medicine, 48, 1291-1299.

King-Spooner, S. (2001). The place of spirituality in psychotherapy. In S. King-Spooner \& C. Newnes (Eds.), Spirituality and Psychotherapy (pp. 28-36). Ross-on-Wye: PCCS Books.

King-Spooner, S. \& Newnes, C. (2001). Spirituality and psychotherapy. Ross-on-Wye: PCCS Books.

Lifton, R.J. (1987). The future of immortality and other essays for a nuclear age. New York: Basic Books.

Lincoln, Y. S. \& Guba, E. G. (1985). Naturalistic Inquiry. Beverly Hills: Sage.

Lindgren, K.N. \& Coursey, R.D. (1995). Spirituality and serious mental illness: a two-part study. Psychosocial Rehabilitation Journal, 18(3), 93-111.

Lonergan, B.J.F. (1972). Method in theology. New York: Herder \& Herder.

Lovinger, R.J. (1996). Considering the religious dimension in assessment and treatment. In E.P. Shafranske (Ed.), Religion and the clinical practice of psychology (pp.327-363). American Psychological Association: Washington DC.

Lukoff, D., Lu, F. \& Turner, R. (1998). From spiritual emergency to spiritual problem: the transpersonal roots of the new DSM-IV category. Journal of Humanistic Psychology, 38(2), 21-50.

Madill, A., Jordan, A. \& Shirley, C. (2000). Objectivity and reliability in qualitative analysis: realist, contextualist and radical constructionist epistemologies. British Journal of Psychology, 91, 1-20.

Marquis, A., Holden, J.M. \& Warren, E.S. (2001). An integral psychology response to Helminiak's (2001) "Treating spiritual issues in secular psychotherapy". Counseling and Values, 45(3), 218-236.

Merrick, E. (1999). An exploration of quality in qualitative research: are 'reliability' and 'validity' relevant? In M. Kopala \& L.A. Suzuki (Eds.), Using qualitative methods in psychology (pp. 25-36). California: Sage. 
Miller, W.R. \& Thoresen, C.E. (2003). Spirituality, religion and health. American Psychologist, 58, 2435.

Myers, J. \& Baker, M. (1998). Religiously committed clinical psychologists, talking. Clinical Psychology Forum, 117, 30-32.

Newnes, C. (2001). Introduction. In S. King-Spooner \& C. Newnes (Eds.), Spirituality and Psychotherapy (pp. 1-4). Ross-on-Wye: PCCS Books.

Nino, A.G. (1997). Assessment of spiritual quests in clinical practice. International Journal of Psychotherapy, 2(2), 193-212.

Parker, I. (1994). Qualitative research. In P. Banister, E. Burman, I. Parker, M. Taylor \& C. Tindall (Eds.), Qualitative methods in psychology: a research guide (pp. 1-16). Buckingham: Open University Press.

Prest, L.A. \& Keller, J.F. (1993). Spirituality and family therapy: spiritual beliefs, myths, and metaphors. Journal of Marital and Family Therapy, 19(2), 137-148.

Reinertsen, A.M. (1993). The private God in the group: the God-image in an object-relations view. Group Analysis, 26, 5-25.

Rowe, D. (2001). What do you mean by spiritual? In S. King-Spooner \& C. Newnes (Eds.), Spirituality and Psychotherapy (pp. 37-46). Ross-on-Wye: PCCS Books.

Samuels, A. (1998). 'And if not now, when?' Spirituality, psychotherapy and politics. Psychodynamic Counselling, 4(3), 349-365.

Shafranske, E.P. \& Malony, H.N. (1990). Clinical psychologists' religious and spiritual orientations and their practice of psychotherapy. Psychotherapy, 27(1), 72-78.

Smail, D. (2001). On not being able to eff the ineffable. In S. King-Spooner \& C. Newnes (Eds.), Spirituality and Psychotherapy (pp. 47-51). Ross-on-Wye: PCCS Books.

Stiles, W.B. (1993). Quality control in qualitative research. Clinical Psychology Review, 13, 593-618.

Strauss, A. \& Corbin, J. (1990). Basics of qualitative research: grounded theory procedures and techniques. Newbury Park: Sage.

Swinton, J. (2001). Spirituality and mental health care: rediscovering a 'forgotten' dimension. London: Jessica Kingsley.

Watts, R.E. (2001). Addressing spiritual issues in secular counseling and psychotherapy: response to Helminiak's (2001) views. Counseling and Values, 45(3), 207-217.

West, W. (2000). Psychotherapy and spirituality: crossing the line between therapy and religion. London: Sage.

Worthington, E.L. (1986). Religious counseling: a review of published empirical research. Journal of Counseling and Development, 64, 421-431.

Worthington, E.L. (2001). Five steps to forgiveness: the art and science of forgiving. Virginia: Crown Publishers.

Wulff, D.M. (1997). Psychology of religion: classic and contemporary. New York: Wiley.

Zohar, D. \& Marshall, I. (2000). SQ: Spiritual Intelligence: the ultimate intelligence. London: Bloomsbury. 